\title{
State of Fire Research and Safety
}

\author{
JAMES G. QUINTIERE \\ Center for Fire Research \\ National Bureau of Standards \\ Gaithersburg, Maryland 20899, USA
}

\begin{abstract}
A review is made of available international statistics on the costs and losses due to fire. Estimates are also made on the level of fire research carried out by different countries. Views are presented on strategies for reducing the losses and costs by fire. An example is given to illustrate a rational use of test data to predict fire growth on materials.
\end{abstract}

\section{INTRODUCTION}

"It takes a disaster to make one cautious" wrote Eddie Foy as he recounted his experiences on the afternoon of December 30, 1903. Eddie Foy was a well-known entertainer appearing at the Iroquois Theater in Chicago, Illinois on that day. He had brought his son Bryan, aged six, to watch the performance of $\mathrm{Mr}$. Bluebeard. The audience was packed with women and children enjoying the Christmas week. During the performance, fire occurred and quickly spread. In eight minutes, 1825 people sought to escape; 602 did not succeed. The building was of fire resistant construction and modern for its day. What went wrong? Some said the fire-blocking stage curtain malfunctioned, exits were poorly marked, there was no fire alarm box, and sprinklers should have been provided for the stage [1]. Should these factors have been obvious before the fire? Perhaps not. "It takes a disaster to make one cautious."

Disastrous fires continue to take their toll. In 1983, a theatre fire in Italy killed 64 people, a hotel fire in turkey claimed 35 lives, and a discotheque fire in Spain killed 79. In the skies over the USA, a fire in a commercial passenger aircraft resulted in 23 fatalities.

Current (1981) USA fire statistics suggest that 7600 deaths due to fire will occur per year. Assuming no substantial change in this death rate ( $34 / 10^{6}$ persons), about one in 400 persons will die by fire in your lifetime ( 75 years). You are likely to have known one.

Could these disasters have been prevented? Can we reduce our risk of death due to fire? Do we fully understand what causes a fire catastrophe? Is fire safety an exact science? Let's explore our state of fire safety and its science and technology. 
Technology is the state of knowledge applied to the production of goods and services in a particular field. Technology is an important ingredif in the economic health of a company, industry or nation. Economic growt depends on technological change, i.e., advances in knowledge that are applied to the market place. Although new scientific discoveries contribute to and promote technological change, it is the dissemination knowledge that contributes to its application.

The technology of fire safety is governed principally by its response tc needs in the market place and our environment. In the production of mar products, issues of fire safety play a role in their design and structur Components of building codes and standard test methods mandate the technological requirements for meeting standards of fire safety. These are usually inflexible requirements that limit the application of new knowledge to fire safety design or new understanding to fire resistance. The technology (both generic and proprietary) for fire safety is set by the criteria of "pass the test" or "meet the requirements".

The technological level of a nation, with its complex array of technological changes, can place a burden on the processes for setting fire safety requirements. Moreover, the inability of the fire safety technology to cope with technological changes in the market place can limit or inhibit such changes. It is not uncommon to have new products applications come along only to be misread by the current fire test metr of record.

The level of technological development of the United States appears to 1 at least twice that of other developed countries of the world (Figure 1; [2]. Thus, it would appear that the level of fire safety technology mus be equal to this challenge. Unfortunately, this is probably not the cas since we place our emphasis on "rule making" to settle issues as opposer to performance standards based on new knowledge.

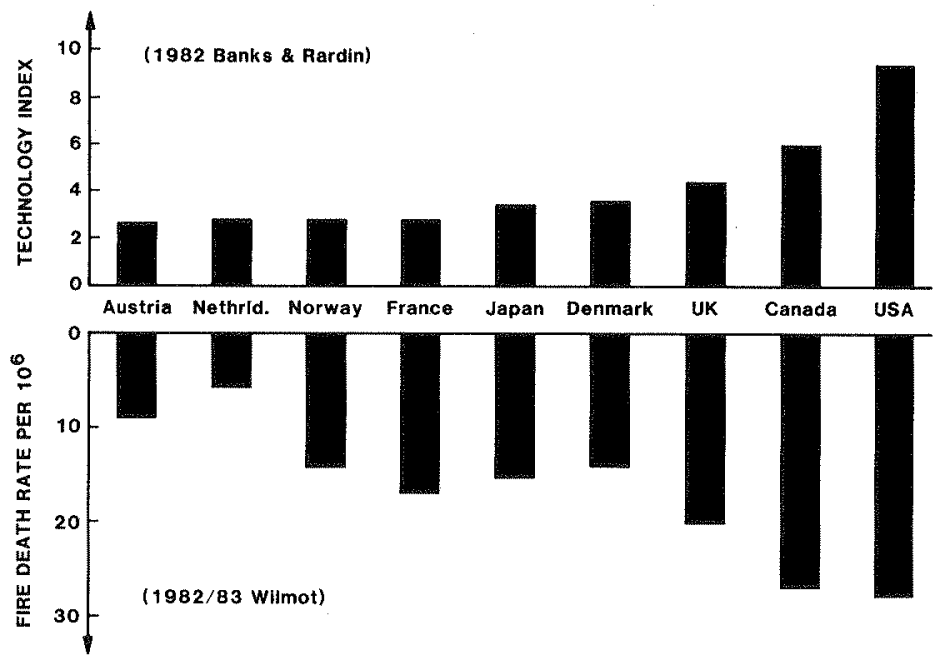

Figure 1. Country technology level and annual fire deaths. 
One measure of the level of fire technology is the great reliance placed on specifications required by standard tests and codes. Indeed, disparities among "national" fire propagation test methods [3] clearly illustrate our lack of unanimity in how to decide a material's fire behavior. These disparities surely add to confusion in the international market place and add to the cost of foreign trade for the products affected.

Another measure of the level of fire technology is the knowledge base of the field. In 1983 about 150 technical articles by USA authors appeared in six technical journals. Yet, no fundamental textbooks exist for the field in the USA. In Japan, at least two texts exist; one for the fire science program at the Science University of Tokyo; the other at Yokohama National University in the curricula of engineering safety. In the USA, the NFPA Handbook provides a chronicle of the fire technology in practice. It provides much useful information on the many subjects related to fire safety; but little in the way of theory in order to develop understanding or flexible design practices. This is consistent with a recent survey of fire protection engineers (SFPE) which indicated preference to design by using the "code" rather than by analytical methods [4].1 of the $2800 \mathrm{SFPE}$ members, about 350 new engineering graduates are needed by the field each year. Of those graduates, only about 258 come from college degree programs in fire protection engineering. Hence, the $75 \%$ that mostly come from other engineering disciplines must learn the field in practice.

The practice of fire safety technology involves knowledge from many disciplines. This contributes to its lack of an organized science base of knowledge. The field involves human behavior, heat and mass transfer, toxicity, detection, suppression, structural behavior, risk, and probably education should also be added. It is interesting to recite from a description of a new program begun at the National Bureau of Standards on fire safety [6].

In a joint undertaking with the National Fire Protection Association and the Underwriters Laboratories, the Bureau aimed at a thorough study of the behavior and safety of building materials in various types of construction under all possible fire conditions. The study would furnish architects, builders, state and city building bureaus, and insurance interests with fundamental engineering data long needed but nowhere available.

But so broad became the scope of the investigation that it soon involved almost everyone of the scientific and engineering laboratories of the Bureau. It included hightemperature measurements, fire tests, and thermal conductivity studies by the Heat Division; solution of composition and construction problems by the Chemistry and Structural Materials Divisions; electrical wiring and safety code studies by the Electrical Division; and the behavior of structural materials under heat as a special study in the Weights and Measures Division.

${ }^{1}$ In a more recent survey [5], this preference reversed. Also, the book, An Introduction to Fire Dynamics, by Dougal Drysdale was published (1985). 
This was the program directed by Simon Ingberg that began in 1914 . It w prompted by the concern that the USA property loss was ten times that of any European country. Also, the NBS Director noted in Congressional testimony that "The greatest (fire) losses are in the cities having fire laws and regulations." Sixty years later, a Presidential Commission on Fire declared: "One basic need is to strengthen the grounding of knowled about fire in a body of scientific and engineering theory, so that real world problems can be dealt with through predictive analyses" [7].

Perhaps it is fair to say that the practice of fire safety is an underdeveloped technology. Its state could be particularly burdensome to an advanced technology and its consequences could be economically costly.

\section{COSTS OF FIRE}

The costs of fire comprise the money spent in the implementation of fire protection and control measures, insurance administrative costs and claims, plus the personal costs in terms of deaths and injuries. One could also include the cost of medical treatments as a direct result of fire injuries and the indirect costs of displacement, relocation, lost production and psychological effects.

A comparison of fire deaths per capita is plotted against the country's technology index. These data for $1982 / 83$ came from Wilmot [8] who list: 15 countries with only Hungary exceeding the USA death rate. Figure 1 suggests the relationship between technology and fire losses previously posed by Banks and Rardin [2]. The highest death rate for Hungary mighy be contrasted with the fact that it has the highest standard of living among the Eastern European countries which is suggestive of its technol, leve1. Although the level or change in technology might be correlatabli with fire statistics, it does not suggest causative factors but does suggest the interplay of more variables in an advanced technological environment.

Some of the monetary costs due to fire and fire safety are shown in Fign 2 in comparisons based on the Gross Domestic Product (GDP) for various developed countries [9]. (The GDP is essentially the Gross National Product (GNP) minus the input of foreign investment). These costs are broken down into the cost of the property lost, the cost needed to prov: fire service operations, the cost of meeting the fire protection needs. the facility and the administrative costs of the fire insurers. Despit variations in these individual costs among the countries listed, it is significant that the total costs are nominally at 1 percent of their GD: The cost of research and development for fire safety might be viewed as indicator of potential reduction in the "costs" of fire. An informal survey (1985) for the USA found $\$ 15$ million for basic fire research whi, contributes to new fundamental knowledge; $\$ 80$ million for special testi standards and education; and roughly $\$ 150 \mathrm{million}$ for product developme to meet fire safety requirements. These results suggest that less than percent of the USA fire costs ( $\$ 37.4$ billion, 1983 [10]) used for fire safety research, development and standards with only 0.05 percent appli, to research. This compares to typical values of 2-3 percent of a developed country's GDP applied to research and development [1].

A measure of a country's interest in fire safety research can be deduce by the staff employed relative to its population. As with direct costs these staff figures are also subject to interpretations of research activities versus other activities. In compiling this measure, shown il 


\section{COST OF FIRE}
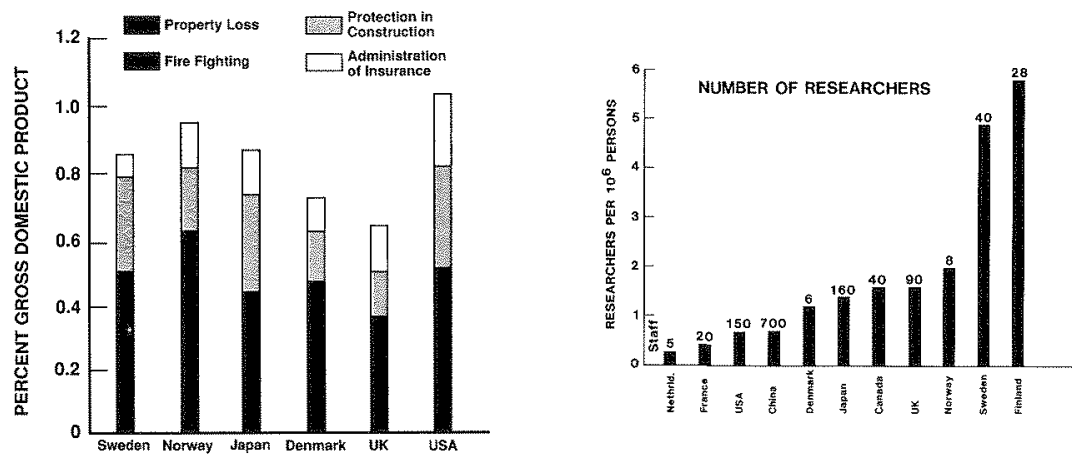

Figure 2. Country costs of fire. Figure 3. Country relative number of fire researchers.

Figure 3, I tried to identify the technical staff of we1l-known institutions engaged in research programs. These numbers represent the pool from which advances in fire safety knowledge can spring. Whether one considers this effect to be adequate or not, is not the total issue, since the transfer of new knowledge into practice is just as critical. The Building Research Board of the National Research Council reported, "The technology base needed to solve fire problems is now evolving. Owneroperators (of buildings) and design professionals have received little education in the use and benefits of this technology base and there is an urgent need for fire protection professionals to translate fire research into terms understandable by designers and the owner-operators they serve" [12]. Thus, in addition to deficiencies in fire research levels, there is perhaps a greater deficiency in the mechanisms and resources for transferring the fire science knowledge base to the users.

\section{PROSPECTS FOR REDUCING FIRE COSTS}

The goal of effective management in fire safety should be to minimize the costs and losses due to fire. Implicit in the term losses are the deaths and injuries associated with fire. Let us examine some major aspects of the costs and losses in order to project some potential indication for their reductions.

The USA has the highest number of fire deaths per capita of any developed country in the world. Based on data for 1981, the death rate was 33.1 per million persons - - a significant drop from 1971 when it was at 43.7 [13]. A study by Gomberg, et a1. [14] derived a 418 reduction in the fatality rate for residences with smoke detectors. In 1981, 66 percent of the homes had detectors, compared to virtually very little in 1971. Based on these facts one can estimate the death rate in 1981 solely due to the detector impact on 1 ife safety [13]. Since about 80 percent of deaths occur in residences, a 41 percent reduction will be applied uniformly to the 1971 death rate, i.e., it is assumed that a11 deaths occur in residences and people are evenly distributed over residences:

1981 Estimated Death

Rate Due to Detector $=43.7[(1-0.41)(0.66)+(1).(0.34)]=31.9$

Intervention 
This value compates favorably with the actual statistic of 33.1 ; moreove a value of 34.2 would have been estimated if we accounted for the fact that only 808 of the fire deaths occur in residences. This follows by taking the residential ( $80 \%$ ) portion of the death rate to be 31.9 and the (20\%) remainder at the 1971 level of 43.7 . Indeed, if one assumed all deaths could be mitigated by detectors, then the death rate might reach: minimum based on detector intervention of 25.3 per million person. This minimum for the USA is still greater than the fire death rates of most industrialized nations. Also, the prevalence of home smoke detectors in other countries is not as great as in the USA. Hence, although the technology of reliable detectors and their current low price appear to have contributed greatly to the USA death rate reduction, it would appeas that other unique but unknown factors inflate the USA fire death rate compared to other industrialized nations.

A reduction in the potential for fire growth, its mitigation, and its control bear on the loss of life, the occurrence of injury, and the damat to property. Property loss in unreported fires has been estimated at $\$ 4$ ? per fire [14]. This might result for a fire involving less than 1 square meter of material, or less than $300 \mathrm{~kW}$ of energy. For a fire much bigger, the opportunity for a non-professional to extinguish it is poor, and the potential for such fires to quickly and fully involve a typically sized residential room is very high. Once a fire spreads beyond a room the chance that it will become a large fire is much greater; e.g., Thomas [16 reports the number of large loss fires (perhaps greater than $\$ 100,000$ today) is related to the cube of the number of fires which left the room of origin. Furthermore, fully involved compartment fires generate a considerable amount of carbon monoxide threatening life at sites remote from the fire origin. Hence, confining fire growth to less than 1 square meter of material could be a desirable goal.

It has been estimated that a combination of smoke detectors and a standar sprinkler could reduce the fire death rate by 588 [14]. Recently, Budnic [17] suggested a figure of $73 \%$ if fast-acting "residential" sprinklers were used instead of the standard sprinklers. Whereas detectors are realizing widespread use, the cost of sprinklers, especially in residences, has inhibited their widespread use. Efforts to reduce this cost or to improve the technology of residential suppression systems is needed to effectively impact the fire losses. It might be contemplated that very little fire research has been directed at suppression - - perhap $15 \%$ at most.

of course while a suppression system could limit a fire's growth in the early stages, ignition and flame spread resistant materials could improve fire safety significantly. It is not necessarily just the development of new materials that is essential, but it is the proper measurement of fire hazard and risk that these materials impart to their environment.

Improved measures of fire hazard analysis can have significant reductions in product development costs as well as in the costs of fire protection i construction.

The cost of fire protection in construction is estimated at $\$ 9$ billion (1983). much of this cost is due to prescribed requirements by the building codes. Yet most codes have discretionary provisions which allow for the use of alternative but equivalently safe designs and constructior practices. Because of the high reliance by the practicing engineers and architects on the codes, these alternatives are not usually exercised, especially since a creditable equivalency level must be demonstrated. Former Secretary of HEW (now HHS), Joseph A. Califano, Jr., stated that i 
order to insure proper fire safety, "...HEW's staff had proposed several hundred pages of detailed, plank-by-plank, nail-by-nail specifications for construction and remodeling of hospitals and nursing homes". ..."Instead, at an estimated savings of $\$ 1$ billion from the cost of complying with the HEW staff proposal, we ordered a simple code drafted that would require hospitals and nursing homes to provide equivalent fire safety protection, but left them the flexibility to determine how [18]". This "simple code" was the Fire Safety Evaluation Systems (FSES) developed by Nelson and Shibe [19]. It is based on equivalency with the NFPA Life Safety Code. The estimated optimum savings in cost compared to implementing the Life Safety Code is 50 percent [20]. Since the FSES has been based on existing fire protection technology; i.e., wisdom and experience, the potential for improving cost reductions further by analytical design methods is enormous. Thus, the recognition and ability to take advantage of flexibilities in the fire codes are beneficial objectives. The Japanese government has recently funded a five-year program to develop design and evaluation methods for building fire safety [21]. Perhaps this will be a first step for a flexible performance fire safety code.

Three other aspects of fire safety and fire consequences could also be improved. First, one research goal from America Burning (p.136) [7] sought to increase fire control capability by more effective extinguishing methods. Perhaps improved cost efficiency could be achieved by the fire services if this goal were realized. Second, liability claims associated with fire are increasing and their costs to society and industry sap more constructive pursuits. Scientific data and analytic methods could positively mitigate these issues, and make more sound the lessons learned. Third, common international understanding of fire safety principles, based on accepted scientific methods, could go a long way for reducing trade barriers and costs of foreign compliance on materials and products.

\section{A RATIONAL APPROACH TO MATERTAL FIRE SAFETY}

A scientific approach to fire safety analysis should improve the use of material test data and help to harmonize fire safety requirements. There is a lack of consensus on the tests to use for evaluating the flammability of interior finish materials. The disparity in results from various international test methods underscores this lack of consensus [3]. As an example, let us examine the prospect of predicting fire growth over a wall lining material in a room subject to a small ignition source. An actual experiment will be examined. Our analysis will be simplified for clarity in illustrating the governing physics. Its ultimate generalization offers the prospect of a rational approach for interior finish fire hazard analysis.

\section{Ignition}

The room fire experiment is displayed in Figure 4 . The only combustible in the room is a T-section of polymethylmethacrylate (PMMA) of $12.7 \mathrm{~mm}$ thickness over the back wall. The ignition source is a line burner diffusion flame $0.15 \mathrm{~m}$ high and $0.30 \mathrm{~m}$ high as shown in Figure 5 . This offers a potential vertical spread region and ceiling jet region that would be indicative of "wind-aided" or concurrent gas flow and flame 

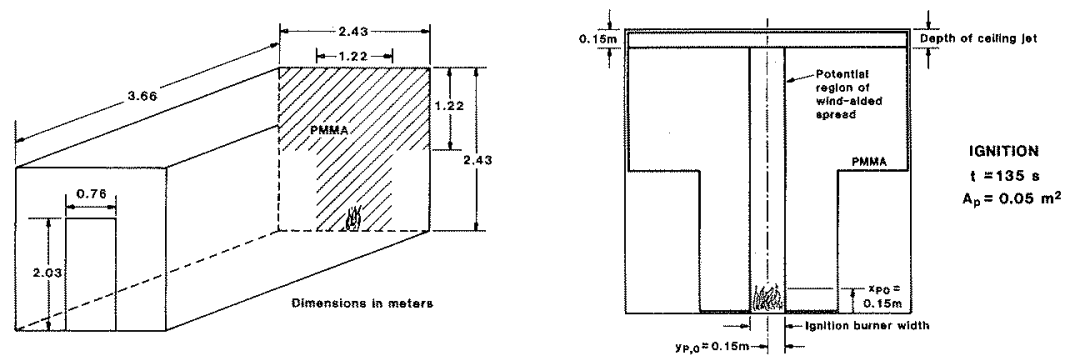

Figure 4. Room wall fire experiment. Figure 5. Ignition of PMMA wall.

spread. The ceiling jet thickness was estimated from the solution by Alpert [22] as 0.06 of the room height. The time to ignite is estimated for the diffusion flame heat flux of $25-30 \mathrm{~kW} / \mathrm{m}^{2}$ [23] by the formula:

$$
t_{i g}=\frac{\pi}{4} \quad\left(\frac{k \rho c\left(\mathrm{~T}_{i g}-\mathrm{T}_{i}\right)}{\dot{q}^{\prime \prime}}\right)^{2}
$$

where $\mathrm{k} \rho \mathrm{c}=1.02\left(\mathrm{~kW} / \mathrm{m}^{2} \mathrm{~K}\right)^{2} \mathrm{~s}$,

and $q^{\prime \prime}=25-30 \mathrm{~kW} / \mathrm{m}^{2}$

following the test data of Harkleroad and Quintiere [24]. The calculate time is $135 \pm 25 \mathrm{~s}$ compared to observed ignition estimated at $94 \mathrm{~s}$. The initial pyrolysis area, $A_{p}$, is calculated as $0.05 \mathrm{~m}^{2}$ based on the burner flame exposure. The objective is to compute the growth of $A_{p}$ in time an its influence by and to the room.

Upward Flame Spread

Upward flame spread is considered along the wind-aided direction, vertically upward and along the ceiling jet. The pyrolysis front, $x_{p}$, $i$ estimated from the experiments of orloff, de Ris and Markstein for PMMA [25]:

$$
\frac{d x_{p}}{d t}=0.004 x_{p}
$$

with $x_{p}$ in $m$ and $t$ in $s$. The effects of external heating and oxygen depletion are not included in Eq. (2), but in hindsight $\mathrm{Eq}$. (2) will be shown adequate for the early stage of fire growth since these effects ar found to be small. Furthermore, in general, one must first determine if spread will occur following ignition, but this is not an issue for PMMA.

Mass Loss Rate

Once pyrolysis begins following ignition, the mass flux, $\dot{m} "$, must be computed. The resultant energy release is a direct measure of the fire hazard potential. Figure 6 shows a sketch of the mass loss behavior as. 


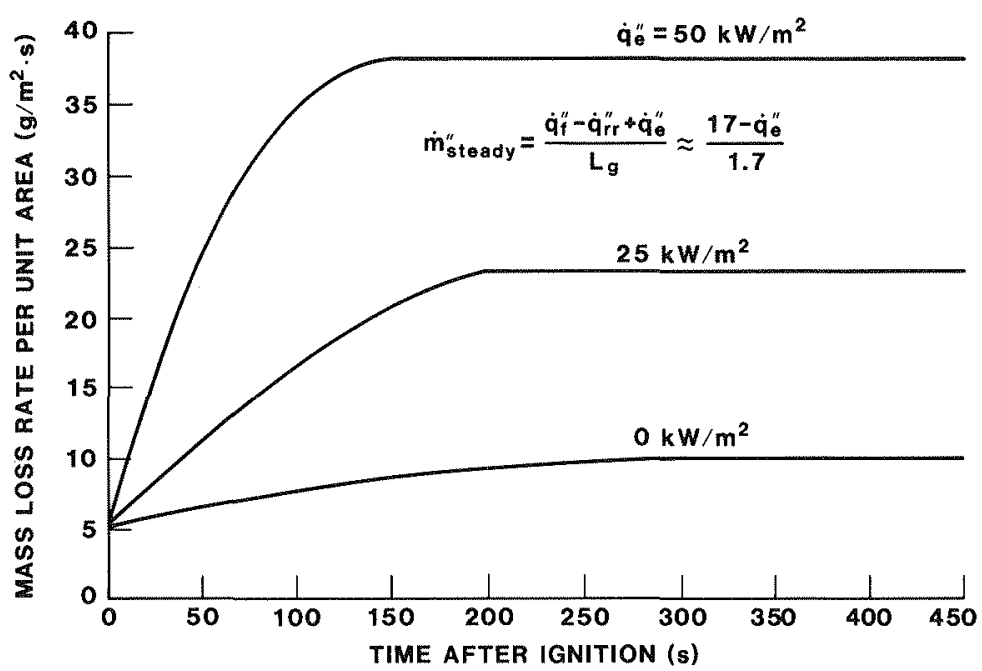

Figure 6. Burning vertical PMMA under external radiant heating.

function of time. For PMMA we can assume steady burning after $300 \mathrm{~s}$ of fire growth. Figure 6 follows from the experimental results of Walton and Twilley [26]. The steady result, sufficient for our analysis, can be given as

$$
\dot{m}_{s s}^{\prime \prime}=\frac{\dot{q}_{f}^{\prime \prime}-\dot{q}_{r r}^{\prime \prime}+\dot{q}_{e}^{\prime \prime}}{L_{g}}\left(g / m^{2}-s\right)
$$

where the heat of gasification, $L_{\mathrm{g}}=1.7 \mathrm{~kJ} / \mathrm{g}$, the reradiation $10 \mathrm{ss}, \dot{\mathrm{q}}_{\mathrm{r} r}^{\mathrm{n}}=$ $10 \mathrm{~kW} / \mathrm{m}^{2}$, and the flame heat flux, $\dot{q}_{f}^{\prime \prime}=27 \mathrm{~kW} / \mathrm{m}^{2}$. The external radiative heat flux is $\dot{q}_{e}^{\prime \prime}$. In general, the transient burning of a material must be included in a complete hazard analysis.

Lateral and Downward Flame Spread

Spread orthogonal to the wind-aided direction is in the direction opposite to the air entrainment. The spread is lateral during the vertical ascent of the flame, and downward once the flame has progressed along the ceiling jet. This extent of spread, $y_{p}$, is estimated for no external heating effects as

$$
\frac{d y_{p}}{d t}=0.12 \mathrm{~mm} / \mathrm{s}[24]
$$

Figure 5 shows the initial value of $y_{p}$.

Pyrolysis Area

For this example of PMMA, the pyrolysis area, Ap, can easily be calculated by using Eqs. (2) and (4) as follows: $2 x_{p} y_{p}$. This assumes that burnout does not occur over our period of interest. Again, in hindsight, this 
assumption is satisfactory based on a nominal burning time of $1500 \mathrm{~s}$ for this PMMA wall burning under initial ambient conditions.

\section{Room Conditions}

The problem we are solving is highly coupled with the fire growth area depending on the room conditions which, in turn, depend on the fire. In the early stage, for this example, this coupling is weak so we will neglect it to some extent. The room upper layer gas temperature $\left(T_{g}\right)$ is estimated by the correlation shown to be adequate for wall fires [27]:

$$
\mathrm{T}_{\mathrm{g}}=\mathrm{T}_{\mathrm{i}}+6.85\left(\frac{\dot{\mathrm{Q}}^{2}}{\mathrm{~A}_{\mathrm{o}} \sqrt{\overline{\mathrm{H}}_{\mathrm{o}} \mathrm{h}_{\mathrm{k}} \mathrm{A}}}\right)^{1 / 3}
$$

where $A_{0}$ is the door area (m)

$\mathrm{H}_{\mathrm{o}}$ is the door height (m)

$A$ is the room surface area $(\mathrm{m})$

$h_{\mathrm{k}}$ is a conductance, $9 \times 10^{-3} \mathrm{~kW} / \mathrm{m}^{2} \mathrm{~K}$ selected here

and

$\dot{Q}$ is the energy release rate, $\mathrm{kW}$.

$$
\dot{\mathrm{Q}}=\left(\begin{array}{l}
\dot{\mathrm{m}}_{\mathrm{m}} \Delta \mathrm{h}_{\mathrm{c}}, \phi \leq 1 \\
\dot{\mathrm{m}}_{\mathrm{a}} \Delta \mathrm{h}_{\mathrm{c}} / \gamma, \phi>1
\end{array}\right)
$$

where $\mathrm{Eq}$. (6a) refers to the fuel-controlled case of sufficient air supply, and (6b) is for the ventilation-limited case. The equivalence ratio, $\phi$, defines the boundary of these two burning domains:

$$
\phi=\frac{\dot{\mathrm{m}}_{\mathrm{a}} / \mathrm{m}}{\gamma}
$$

here $\gamma$ is the stoichiometric fuel to air ratio for PMMA, $0.12 ; \Delta h_{c}$ is th heat of combustion for PMMA, $25 \mathrm{~kJ} / \mathrm{g}$; and the air flow rate $\mathrm{m}_{\mathrm{a}}$ can be estimated from the doorway dimensions and $\mathrm{T}_{\mathrm{g}}[$ [e.g. 27]. The mass loss rate follows from Eq. (3):

$$
\dot{\mathrm{m}}=\dot{\mathrm{m}}^{\prime \prime} \mathrm{A}_{\mathrm{p}}
$$

where the external heat flux $\dot{q}_{\theta}^{\prime \prime}$, in $\mathrm{Eq}$. (3) is determined from $\mathrm{T}_{\mathrm{g}}$ as purely radiative heat transfer.

The gas concentrations are estimated from $\phi$ using the results of Beyler for PMMA [28].

\section{Results}

The procedure is to compute $A_{p}$ at a given time, and then compute the roo conditions. For the next time, the previous room conditions are used to estimate the effect of room feedback on the spread process. The results of these computations are shown in Table 1 . Certainly they could be refined through a more detailed computer solution, but the order of magnitude of their results is not expected to change. Let us examine 
these results in terms of the actual fire progression in the experiment. Note, in the Table that $\Delta \mathrm{A}_{\mathrm{p}}$ is defined as the extent of pyrolyzed area beyond that due to wind-aided spread alone which would only have been confined to the band bounded by the dashed-lines in Figure 5 . This band will be retained in subsequent figures to visualize these differences. Table 1 shows that in the early growth phase through $835 \mathrm{~s}$ room feedback is relatively not significant, but in the next $160 \mathrm{~s}$ the oxygen plunges toward $0 \%$ and thermal feedback increases $\dot{m}^{\prime \prime}$ by 10 times over its initial value. In the middle of this accelerated growth period of $160 \mathrm{~s}$, the fire reaches the ventilation limit state $(\phi>1)$ and significant $C O$ is produced as a result of incomplete combustion within the room. The fire conditions beyond the room will determine whether subsequent combustion will diminish this co concentration. In the early growth period, 358 of the spread is due to lateral and downward spread modes; and both modes appear to contribute equally to what might be termed "flashover" at $965 \mathrm{~s}$.

\section{Table 1}

Results of Computations for Wall Fire Spread

\begin{tabular}{|c|c|c|c|c|c|c|c|c|c|}
\hline \multirow[b]{2}{*}{$\underset{s}{T}$} & \multirow[b]{2}{*}{$\stackrel{\mathrm{A}_{\mathrm{p}}}{\mathrm{m}^{2}}$} & \multirow[b]{2}{*}{$\stackrel{\Delta A_{g}}{m^{2}}$} & \multirow[b]{2}{*}{$\begin{array}{l}\mathrm{m}^{\prime \prime} \\
\mathrm{g} / \mathrm{m}^{2}-\mathrm{s}\end{array}$} & \multirow[b]{2}{*}{$\begin{array}{l}\dot{\mathrm{Q}} \\
\mathrm{kW}\end{array}$} & \multirow[b]{2}{*}{${ }^{\mathrm{T}} \mathrm{C}$} & \multirow[b]{2}{*}{$\begin{array}{l}\mathrm{m}_{\mathrm{a}} \\
\mathrm{g} / \mathrm{s}\end{array}$} & \multicolumn{3}{|c|}{ Mass Fractions } \\
\hline & & & & & & & $\phi$ & $\mathrm{Y}_{2}$ & $\mathrm{Y}_{\mathrm{CO}}$ \\
\hline 135 & 0.05 & 0 & 5 & 6 & 48 & 100 & 0.02 & 0.233 & 0 \\
\hline 335 & 0.12 & 0.016 & 6 & 18 & 73 & 200 & 0.04 & 0.23 & 0 \\
\hline 535 & 0.29 & 0.07 & 7 & 50 & 120 & 250 & 0.07 & 0.22 & 0 \\
\hline 735 & 0.74 & 0.24 & 8 & 148 & 220 & 400 & 0.12 & 0.20 & 0 \\
\hline 835 & 1.14 & 0.41 & 8 & 220 & 280 & 450 & 0.16 & 0.19 & 0 \\
\hline 935 & 1.59 & 0.50 & 13 & 515 & 474 & 550 & 0.31 & 0.15 & 0 \\
\hline 965 & 3.72 & 2.18 & 21 & 200 & 828 & 650 & 1.0 & 0.06 & 0.02 \\
\hline 995 & $4.47^{n}$ & 2.88 & $50 \quad 12$ & 200 & 828 & 650 & 2.8 & 0 & 0. \\
\hline
\end{tabular}

"maximum available

The accuracy of the above analysis is open to question because of its mathematical approximations and the lack of certainty in the physical models. However, the phenomenological scope of the analysis is believed to be complete so that no major effects have been excluded. Subsequent analysis of the experimental results by Lee [29] can be included to examine the accuracy. We shall only consider the fire spread extent given by flame coverage photographs and surface thermocouple measurements. Figures 7-9 contrast the results computed and the corresponding experimental state based on nearly equivalent $A_{p}$ values. For example, in Figure $7 b$ the pyrolysis zone at $490 \mathrm{~s}$ from interpreting Lee's data [29] is nearly equal to the computed values of $x_{p}=1.65 \mathrm{~m}$ and $y_{p}=0.7$ at $735 \mathrm{~s}$. Thus, in all of these comparisons the experimental results are $200-300 \mathrm{~s}$ faster than our estimated results. Certainly, our analysis must be improved and generalized to other materials, but this illustration does offer an indication of what is possible. 


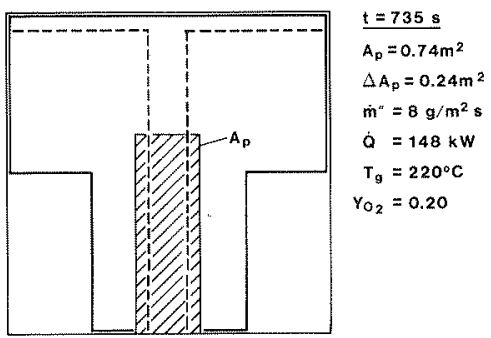

Figure 7a. Predicted results at $735 \mathrm{~s}$.

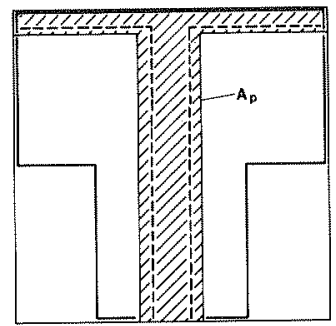

$t=935 \mathrm{~s}$

$A_{p}=1.59 \mathrm{~m}^{2}$

$\Delta A_{P}=0.5 \mathrm{~m}^{2}$

$\dot{\mathrm{m}}^{\prime \prime}=13 \mathrm{~g} / \mathrm{m}^{2} \mathrm{~s}$

$\dot{Q}=515 \mathrm{~kW}$

$\mathrm{T}_{\mathrm{g}}=474^{\circ} \mathrm{C}$

$\dot{q}_{a}=17 \mathrm{~kW} / \mathrm{m}^{2}$

$Y_{\mathrm{O}_{2}}=0.15$

Figure 8a. Predicted results at $835 \mathrm{~s}$.

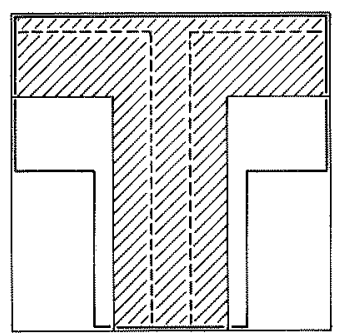

$t=965 \mathrm{~s}$

$A_{p}=3.8 \mathrm{~m}^{2}$

$\triangle A_{P}=2.18 \mathrm{~m}^{2}$

$\dot{\mathrm{m}}^{\prime \prime}=21 \mathrm{~g} / \mathrm{m}^{2} \mathrm{~s}$

$\dot{0}=1230 \mathrm{~kW}$

$T_{9}=830^{\circ} \mathrm{C}$

$\phi=\frac{\mathbf{m} / \mathbf{m}_{\mathrm{alr}}}{\gamma_{\mathrm{fa}}}=1$

$\mathrm{Y}_{\mathrm{O}_{2}}=0.06$

$Y_{C O}=0.02$

Figure 9a. Predicted results at $965 \mathrm{~s}$.

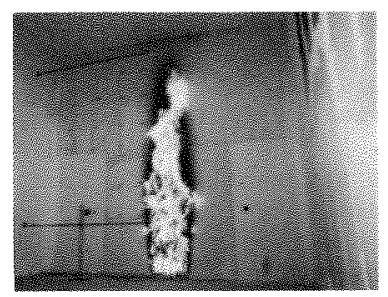

Figure $7 \mathrm{~b}$, Experimental result: at $490 \mathrm{~s}$.

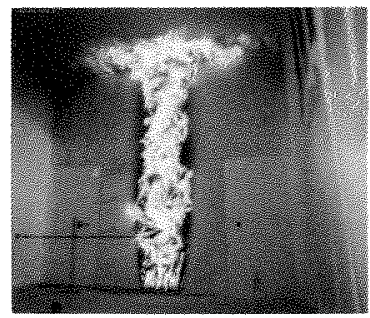

Figure 8b. Experimental result: at $604 \mathrm{~s}$.

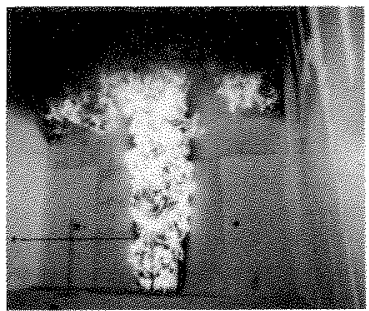

Figure 9b. Experimental results at $660 \mathrm{~s}$. 


\section{CONCLUDING REMARKS}

- We have an opportunity to bring scientific knowledge to bear on the practice of fire safety -. an underdeveloped technology.

- As researchers, we must look for opportunities to translate sound technical advances into practice.

- As practitioners, we must stretch our knowledge base to learn new concepts and approaches for fire safety.

- Fire is costly in terms of lives and goods; the practice of safety must keep pace with technology in the world we live.

\section{REFERENCES}

1. Lyons, P.L., Fire in America!, NFPA, Boston, MA, 1976.

2. Banks, J. and Rardin, R.L., "International Comparison of Fire Loss", Fire Technology.

3. Thomas, P.H., "Recent Developments and Trends in Fire Testing for Fire Growth in Buildings", Comb. Sci. and Technology., v39, 1984.

4. Profile of the Fire Protection Engineer, Soc. of Fire Prot. Engr., Aug. 1984.

5. Profile of the Fire Protection Engineer, Soc. of Fire Prot. Engr., Sept. 1986.

6. Cochrane, R.C., Measures for Progress - A History of the National Bureau of Standards, U.S. Dept. of Commerce, p131, 1966.

7. Bland, R.E., et al, America Burning - The Report of the National Commission on Fire Prevention and Control, Lib. of Cong. No. 73$600022,1973$.

8. Wilmot, T., ed, World Fire Statistics Centre, Bulletin 4, The Geneva Assoc, , July 1986.

9. Ibid, 3, August 1985 .

10. Hal1, J.R., "The Total Cost of Fire in the USA", Fire Journal, May 1986.

11. Statistical Abstract of the United States, 104th Ed., p597, 1984.

12. "Improving Communications Between Fire Researchers and Building OwnerOperators, Building Research Board, Commission on Engineering and Technical Systems", National Research Council, National Academy Press, Washington, DC, 1985.

13. "Fire in the United States", 4th Ed., Federal Emergency Management Agency. 
14. Gomberg, A., Buchbinder, B., and offensend, F.J., "Evaluating Alternative Strategies for Reducing Residential Fire Loss - The Fire Loss Model", National Bureau of Standards, NBSIR 82-2551, August 198

15. Fire Deaths, Causes and Strategies for Control, Technomics Publishir Co., Inc., Lancaster, PA, 1984.

16. Quintiere, J., "The Spread of Fire from a Compartment - A Review", Amer. Soc. for Testing and Materials, STP 685, p141, 1980.

17. Budnick, E.K., "Estimating Effectiveness of the State-of-the-Art Detectors and Automatic Sprinklers on Life Safety in Residential Occupancies", Fire Technology., v20, n3, August 1984.

18. Califano, J.A., Governing America, An Insider's Report from the Whit House and the Cabinet, Simon and Schuster, New York, NY, p154, 1981.

19. Nelson, H.E. and Shibe, A.J., "A System for Fire Safety Evaluation o Health Care Facilities", National Bureau of Standards, NBSIR 78-1555 1 , November 1978.

20. Chapman, R.E., "A Cost-Conscious Guide to Fire Safety in Health Care Facilities", National Bureau of Standards, NBSIR 82-2600, December 1982.

21. Suzuki, H., "Aspects of Fire Research in Japan", Fire and Materials, v8, no. 3, 1984 .

22. Alpert, R.L., "Fire Induced Turbulent Ceiling Jet", FMRC Ser. No. 19722-2, Factory Mutual Research, Norwood, MA, May 1971.

23. Quintiere, J., Harkleroad, M. and Hasemi, Y., "Wall Flames and Implications for Upward Flame Spread", Combustion Science and Technology, 48, 1986.

24. Quintiere, J. and Harkleroad, M., "New Concepts for Measuring Flame Spread Properties", Fire Safety Science and Engineering, ed. T.Z. Harmathy, Amex. Soc. for Testing and Materials, ASTM STP 822, 1985.

25. Orloff, L., de Ris, J. and Markstein, G.H., 15th Symp. on Combustior The Combustion Institute, Pittsburgh, PA, 183, 1975.

26. Walton, W.D. and Twilley, W.H., "Heat Release and Mass Loss Rate Measurements for Selected Materials", National Bureau of Standards, NBSIR 84-2960, 1984.

27. McCaffrey, B.J., Quintiere, J.G. and Harkleroad, M., Fire Technology 17, p90, May 1981 .

28. Beyler, C.I., "Major Species Production by Solid Fuels in a Two Laye Compartment Fire Environment", Fire Safety Science, Proc. 1st Int. Symp., Hemisphere Pub. Corp., NY, p431, 1986.

29. Lee, B., Private Communications, National Bureau of Standards, Feb. $18,1987$. 